\title{
Фотолюминесценция аморфных и кристаллических кремниевых нанокластеров в сверхрешетках из нитрида и оксида кремния
}

\author{
(С) Д.В. Шулейко ${ }^{1}$, С.В. Заботнов ${ }^{1,2,3}$, Д.М. Жигунов ${ }^{1}$, А.А. Зеленина ${ }^{4}$, \\ И.А. Каменских ${ }^{1,2}$, П.К. Кашкаров ${ }^{1,2,3}$ \\ ${ }^{1}$ Московский государственный университет им. М.В. Ломоносова (физический фракультет), \\ 119991 Москва, Россия \\ ${ }^{2}$ Национальный исследовательский центр „Курчатовский институт“, \\ 123182 Москва, Россия \\ ${ }^{3}$ Московский физико-технический институт (факультет нано-, био-, информационных и когнитивных технологий), \\ 141700 Долгопрудный, Россия \\ ${ }^{4}$ Новосибирский государственный университет, \\ 630090 Новосибирск, Россия \\ E-mail: shuleyko.dmitriy@physics.msu.ru
}

(Получена 10 мая 2016 г. Принята к печати 18 мая 2016 г.)

Исследованы фотолюминесцентные свойства сверхрешеток на основе нитрида и оксида кремния, изготовленных методом плазмохимического осаждения из газовой фазы. В структурах, отожженных при температуре $1150^{\circ} \mathrm{C}$, зарегистрированы пики фотолюминесценции в районе 1.45 эВ, обусловленные рекомбинацией экситонов в кремниевых нанокристаллах, формируемых в результате отжига. Наряду с этим были зарегистрированы пики, вызванные рекомбинацией на дефектах, существующих на границе нанокристаллов и матрицы нитрида кремния. Структуры, отожженные при температуре $900^{\circ} \mathrm{C}$, имеют ряд пиков фотолюминесценции в диапазоне 1.3-2.0 эВ, обусловленных как дефектами, так и рекомбинацией экситонов в аморфных кремниевых нанокластерах, формирующихся при используемой температуре отжига. Наблюдаемые особенности всех спектров фотолюминесценции подтверждаются характером ее кинетики.

DOI: 10.21883/FTP.2017.02.44106.8323

\section{1. Введение}

Оптические свойства кремниевых нанокластеров в различных диэлектрических матрицах представляют значительный интерес для оптоэлектроники, поскольку в таких структурах, в отличие от объемного кремния, наблюдается эффективная фотолюминесценция (ФЛ) [1-13]. В частности, перспективным является создание светоизлучающих элементов на основе кремниевых нанокристаллов в кремнийсодержащей матрице и последующее их интегрирование в устройства нанофотоники $[1,3]$. К настоящему времени достаточно детально изучены оптические свойства кремниевых нанокристаллов, внедренных в оксид кремния [1-4]. Обладая ярко выраженными фотолюминесцентными свойствами, такие структуры тем не менее имеют ряд недостатков из-за большой ширины запрещенной зоны используемого в качестве матрицы оксида кремния $(\sim 9$ эВ $)$ и, как следствие, его низкой проводимости [1]. Поэтому более перспективным в оптоэлектронике в качестве матрицы для кремниевых нанокристаллов представляется нитрид кремния, поскольку он обладает меньшей шириной запрещенной зоны [4] и более высокой проводимостью [14]. Кроме того, варьируя концентрацию атомов азота в нитриде кремния, можно контролируемым образом изменять ширину его запрещенной зоны в пределах от 2.5 до 5 эВ $[15,16]$.

Для получения кремниевых нанокристаллов в матрице оксида или нитрида кремния могут использоваться различные методы: плазмохимическое осаждение из газовой фазы $[2,5,17,18]$, магнетронное распыление [14], лазерная абляция [19], ионная имплантация [20]. Важно отметить при этом, что в первом из перечисленных способов возможно эффективно реализовать контроль за размером формируемых нанокристаллов, осаждая многослойную структуру в виде сверхрешетки из слоев с избыточной концентрацией кремния $\left(\mathrm{SiN}_{x}\right.$ или $\left.\mathrm{SiO}_{x}\right)$, чередующихся с барьерными слоями из стехиометрического оксида кремния $\mathrm{SiO}_{2}[3,8]$ или нитрида кремния $\mathrm{Si}_{3} \mathrm{~N}_{4}[4,14,17,21]$ толщиной несколько нанометров. Такие барьерные слои эффективно ограничивают рост образующихся нанокристаллов в пределах слоя с избытком кремния. Для формирования кремниевых нанокристаллов в таких сверхрешетках необходима температура не менее $1000^{\circ} \mathrm{C}$ - при более низких температурах происходит образование преимущественно аморфных нанокластеров [22]. При этом для достижения более высокой проводимости сверхрешетки, что важно при использовании данных структур в оптоэлектронике, в качестве материала матрицы целесообразно использовать нитрид кремния $[4,15,16]$.

Фотолюминесцентные свойства многослойных структур $\mathrm{SiN}_{x} / \mathrm{Si}_{3} \mathrm{~N}_{4}$ и $\mathrm{SiO}_{x} / \mathrm{Si}_{3} \mathrm{~N}_{4}$ сильно зависят как от изначальной стехиометрии осаждаемых слоев $\mathrm{SiN}_{x}, \mathrm{SiO}_{x}$, так и от параметров термического отжига, используемого для получения кремниевых нанокристаллов в объеме пленок $[15,16,22]$. Эти два фактора влияют как на размер кремниевых нанокристаллов, так и на концентрацию дефектов в окружающей матрице. При этом концентрация безызлучательных дефектов при отжиге может как увеличиваться за счет дегидрогенизации матрицы, так и 
уменьшаться за счет роста доли упорядоченной кристаллической фазы и уменьшения количества оборванных связей $[21,22]$, влияя как на общую интенсивность ФЛ, так и на интенсивность отдельных пиков.

Исследования фотолюминесцентных свойств структур на основе нитрида кремния с кремниевыми нанокристаллами [4,14-17,21-25] (в том числе и структур в виде сверхрешеток $[4,14,17,21])$, изготовленных методом плазмохимического осаждения из газовой фазы, показывают, что максимумы ФЛ в основном лежат в видимой области спектра, а возбуждение является однофотонным при использовании лазерного излучения ближнего ультрафиолетового и видимого диапазонов от 325 до 532 нм. Пики при этом трактуются по-разному: наблюдаемая ФЛ может быть обусловлена как излучательными дефектами в матрице нитрида кремния $[4,15,22]$ и на границе нанокристалл-матрица [16] или переходами между состояниями в „хвостах“ зон в аморфной матрице нитрида кремния [24], так и экситонами в кремниевых нанокристаллах $[14,15,22,23,25]$ или аморфных кремниевых нанокластерах $[16,22]$. Для последнего случая в качестве подтверждения часто приводится сдвиг пика ФЛ в синюю область при уменьшении размера нанокристаллов [23]. Однако не всегда можно достоверно определить происхождение ФЛ в структурах на основе нитрида кремния [4]. Например, сдвиг, похожий на размерное квантование в нанокристаллах $\mathrm{Si}$, может быть объяснен и уширением щели подвижности носителей заряда при изменении стехиометрии аморфной матрицы [24]. При этом не всегда наличие кремниевых нанокристаллов в структурах на основе нитрида кремния достоверно подтверждено [26], а при наличии кремниевых нанокристаллов в объеме образца соответствующая ФЛ может быть подавлена безызлучательными переходами [4]. Например, люминесценция, которая наблюдалась в работе [4] в сверхрешетках на основе нитрида кремния, была вызвана не экситонной рекомбинацией в кремниевых нанокристаллах, а излучательными дефектами в матрице из нитрида кремния, при этом сдвиг пика ФЛ был вызван интерференционными эффектами.

Таким образом, несмотря на большое количество проведенных исследований, до сих пор нет общей концепции для описания ФЛ в подобных структурах, представляющих собой сверхрешетку из чередующихся слоев из нитрида и субнитрида (субоксида) кремния с кремниевыми нанокристаллами [4,15-17,23-25]. Поэтому исследования фотолюминесцентных свойств наноструктур на основе нитрида кремния не теряют своей актуальности как с фундаментальной, так и с прикладной точек зрения.

В данной работе показана возможность создания сверхрешеток на основе нитрида кремния с кремниевыми нанокристаллами. Проведено сравнение фотолюминесцентных характеристик данных структур со свойствами образцов на основе оксида кремния, сверхрешеток из чередующихся слоев нитрида и оксида кремния, а также структур, отожженных при температуре $900^{\circ} \mathrm{C}$, меньшей, чем необходима для формирования кремниевых нанокристаллов.

\section{2. Экспериментальные образцы и методики}

Исследуемые образцы представляли собой сверхрешетки на основе оксида и нитрида кремния, полученные методом плазмохимического осаждения из газовой фазы со следующими параметрами: мощность высокочастотного излучения 15 Вт, частота 13.56 МГц, температура подложки $375^{\circ} \mathrm{C}$. Осаждение осуществлялось на подложку монокристаллического кремния $n$-типа проводимости с кристаллографической ориентацией поверхности (100). Более детальное описание методики изготовления образцов содержится в работах [4,27].

Сформированные структуры представляли собой сверхрешетки из 20 пар чередующихся барьерных слоев из оксида кремния $\mathrm{SiO}_{2}$ или нитрида кремния $\mathrm{Si}_{3} \mathrm{~N}_{4}$ и слоев из субоксида кремния $\mathrm{SiO}_{0.93}$ или субнитрида кремния $\mathrm{SiN}_{0.8}$ с избытком кремния, называемых далее активными слоями. Всего было изготовлено 3 типа образцов, различие между которыми заключается в составе как активных, так и барьерных слоев: образцы первого типа (SO) содержат чередующиеся слои $\mathrm{SiO}_{0.93}$ и $\mathrm{SiO}_{2}$, второго типа $(\mathrm{SO} / \mathrm{SN})-\mathrm{SiO}_{0.93}$ и $\mathrm{Si}_{3} \mathrm{~N}_{4}$, третьего $(\mathrm{SN})-\mathrm{SiN}_{0.8}$ и $\mathrm{Si}_{3} \mathrm{~N}_{4}$.

После изготовления проводился отжиг полученных структур при температурах 900 и $1150^{\circ} \mathrm{C}$ в атмосфере азота в течение 1 ч. В результате отжига при температуpe $1150^{\circ} \mathrm{C}$ происходило образование кремниевых нанокристаллов в активных слоях пленки, что подтверждается исследованиями методом рентгеновской дифракции и методом просвечивающей электронной микроскопии в различных режимах (см., например, [4,27]), при этом диаметр нанокристаллов приблизительно соответствует толщине исходных активных слоев. Таким образом, всего было изготовлено для исследования 6 образцов, различающихся составом и температурой отжига. Толщины активных слоев одинаковы, барьерных - различаются в результате выбора наиболее оптимальных значений из предыдущих исследований [14]. Параметры изготовленных образцов представлены в табл. 1 .

Были проведены исследования спектров и кинетики ФЛ всех образцов. Измерения проводились при комнатной температуре с помощью спектрального комплекса на базе монохроматора/спектрографа SOLAR TII MS3504i, позволяющего регистрировать спектры в видимом и ближнем инфракрасном диапазонах (до 1100 нм) при помощи цифровой камеры с ПЗС-матрицей Proscan HS 101H. В качестве источника возбуждения использовался непрерывный гелий-кадмиевый лазер, генерирующий излучение с длиной волны 325 нм и выходной мощностью 30 мВт.

Для измерения кинетики ФЛ дополнительно использовался фотоэлектронный умножитель Hamamatsu R928, в качестве источника возбуждения - эксимерный импульсный лазер CL-5100, работающий на частоте 10 Гц и генерирующий излучение с длиной волны 248 нм, длительностью импульсов 20 нс и энергией в импульce 20 мДж. Измерения проводились на длине волны 800 нм. 
Таблица 1. Стехиометрический состав и толщина слоев многослойных пленок

\begin{tabular}{|c|c|c|c|c|c|}
\hline \multirow{2}{*}{ Образец } & \multicolumn{2}{|c|}{$\begin{array}{c}\text { Активный слой } \\
\text { (с избытком кремния) }\end{array}$} & \multicolumn{2}{|c|}{ Барьерный слой } & \multirow{2}{*}{$\begin{array}{c}\text { Температура отжига, } \\
{ }^{\circ} \mathrm{C}\end{array}$} \\
\hline & материал & толщина, нм & материал & толщина, нм & \\
\hline SO-900 & \multirow{4}{*}{$\mathrm{SiO}_{0.93}$} & \multirow{6}{*}{3} & \multirow{2}{*}{$\mathrm{SiO}_{2}$} & \multirow{2}{*}{1} & 900 \\
\hline SO-1150 & & & & & 1150 \\
\hline $\mathrm{SO} / \mathrm{SN}-900$ & & & \multirow{4}{*}{$\mathrm{Si}_{3} \mathrm{~N}_{4}$} & \multirow{4}{*}{1.5} & 900 \\
\hline $\mathrm{SO} / \mathrm{SN}-1150$ & & & & & 1150 \\
\hline SN-900 & \multirow{2}{*}{$\mathrm{SiN}_{0.8}$} & & & & 900 \\
\hline SN-1150 & & & & & 1150 \\
\hline
\end{tabular}

\section{3. Результаты и их обсуждение}

Максимум ФЛ для структур всех трех типов, отожженных при температуре $1150^{\circ} \mathrm{C}$ (рис. $\left.1, a, b, c\right)$, приходится на диапазон 1.40-1.48 эВ. Данный пик имеет наибольшую интенсивность в спектре. Кроме того, если для образца SO-1150 на основе чередующихся слоев оксида кремния наблюдается только упомянутый единичный максимум (рис. 1, $a$ ), то для двух других структур (SO/SN-1150 и $\mathrm{SN}-1150)$ отчетливо наблюдается дополнительная полоса вблизи 1.9 эВ (рис. $1, b, c)$, что соответствует длине волны $\sim 620$ нм. Аппроксимация измеренных спектров ФЛ этих структур несколькими пиками гауссовой формы выявляет наличие еще одного пика с промежуточной энергией (вблизи 1.7 эВ, или 730 нм). Таким образом, спектры ФЛ наилучшим образом аппроксимируются одним или тремя пиками: спектр образца SO-1150 состоит из одного пика с максимумом около 1.48 эВ, а спектры образцов $\mathrm{SO} / \mathrm{SN}-1150$ и $\mathrm{SN}-1150$ - из трех полос с максимумами при 1.43, 1.73, 1.88 эВ и 1.40, 1.66, 2.00 эВ соответственно.

Таким образом, можно предположить наличие нескольких механизмов ФЛ в исследуемых образцах. Пики с более высокой энергией, наиболее вероятно, соответствуют люминесценции дефектов матрицы или дефектов на границе раздела 〈нанокристалл〉-матрица, причем в структуре SO-1150 люминесценция дефектов не наблюдается, а в двух других структурах имеются два типа люминесцирующих дефектных центров. Люминесценция дефектов в нитридной матрице исследована в работах [28-32]. Пики люминесценции дефектов $\mathrm{N}_{4}^{+}$ и $\mathrm{N}_{2}^{0}$ находятся при энергиях 1.8 и 2.1 эВ, что близко к полученным нами значениям. Следует отметить, что в нашем случае помимо дефектов матрицы вклад могут вносить дефекты на границах раздела нанокристаллов кремния и матрицы.

Пики с энергией из диапазона 1.40-1.48 эВ, присутствующие в спектрах всех трех типов структур, соответствуют, по нашему мнению, ФЛ кремниевых нанокристаллов, диаметр $D$ которых можно оценить по положению данных максимумов в спектре $[23,29]$, используя формулу [18]

$$
E_{\text {gap }}(D)=E_{\text {gap }}(\infty)+\frac{A}{D^{2}},
$$

где $E_{\text {gap }}(\infty)$ - ширина запрещенной зоны в объемном кристаллическом кремнии (1.12 эВ), $A$ - константа, равная 3.57 эВ·нм ${ }^{2}$ для сферических нанокристаллов [18,33]. Рассчитанный по формуле (1) средний диаметр нанокристаллов равен $(3.1 \pm 0.8)$ нм для SO-1150, $(3.4 \pm 1.1) \mathrm{HM}$ для $\mathrm{SO} / \mathrm{SN}-1150$ и $(3.6 \pm 0.6)$ нм для $\mathrm{SN}-1150$, что приближенно соответствует толщинам активных слоев в данных структурах [4]. Наблюдаемую погрешность можно объяснить отличием формы кремниевых нанокристаллов от сферической.

Спектры ФЛ образцов, отожженных при температуре $900^{\circ} \mathrm{C}$, также были проанализированы путем аппроксимации пиками гауссовой формы. Спектр структуры первого типа (SO-900), представленный на рис. 1, $d$, может быть аппроксимирован единичным пиком гауссовой формы. Максимальная интенсивность ФЛ данной структуры наблюдается при энергии 1.45 эВ. В случае многослойных пленок второго (SO/SN-900) и третьего (SN-900) типов можно выделить несколько пиков (рис. 1, e,f). ФЛ структуры SO/SN-900, состоящей из активных слоев на основе оксида кремния и барьерных слоев из нитрида кремния, имеет максимум около 1.4 эВ и наилучшим образом аппроксимируется двумя пиками. Второй пик в спектре образца $\mathrm{SO} / \mathrm{SN}-900$ имеет максимум около 2.0 эВ. Спектр структуры на основе нитрида кремния (SN-900) имеет максимум интенсивности при энергии 1.33 эВ, и может быть аппроксимирован тремя пиками с максимумами около $1.28,1.40$ и 1.55 эВ. При этом форма спектров схожа с формой спектров соответствующих структур, отожженных при $1150^{\circ} \mathrm{C}$. Однако, как показано в ряде предыдущих работ [4,22,27], отжиг при температуре $<1000^{\circ} \mathrm{C}$ не приводит к формированию кремниевых нанокристаллов. В данном случае могут формироваться только аморфные кремниевые нанокластеры [22].

На рис. 2 представлены кривые затухания ФЛ, измеренные на длине волны 800 нм при возбуждении 

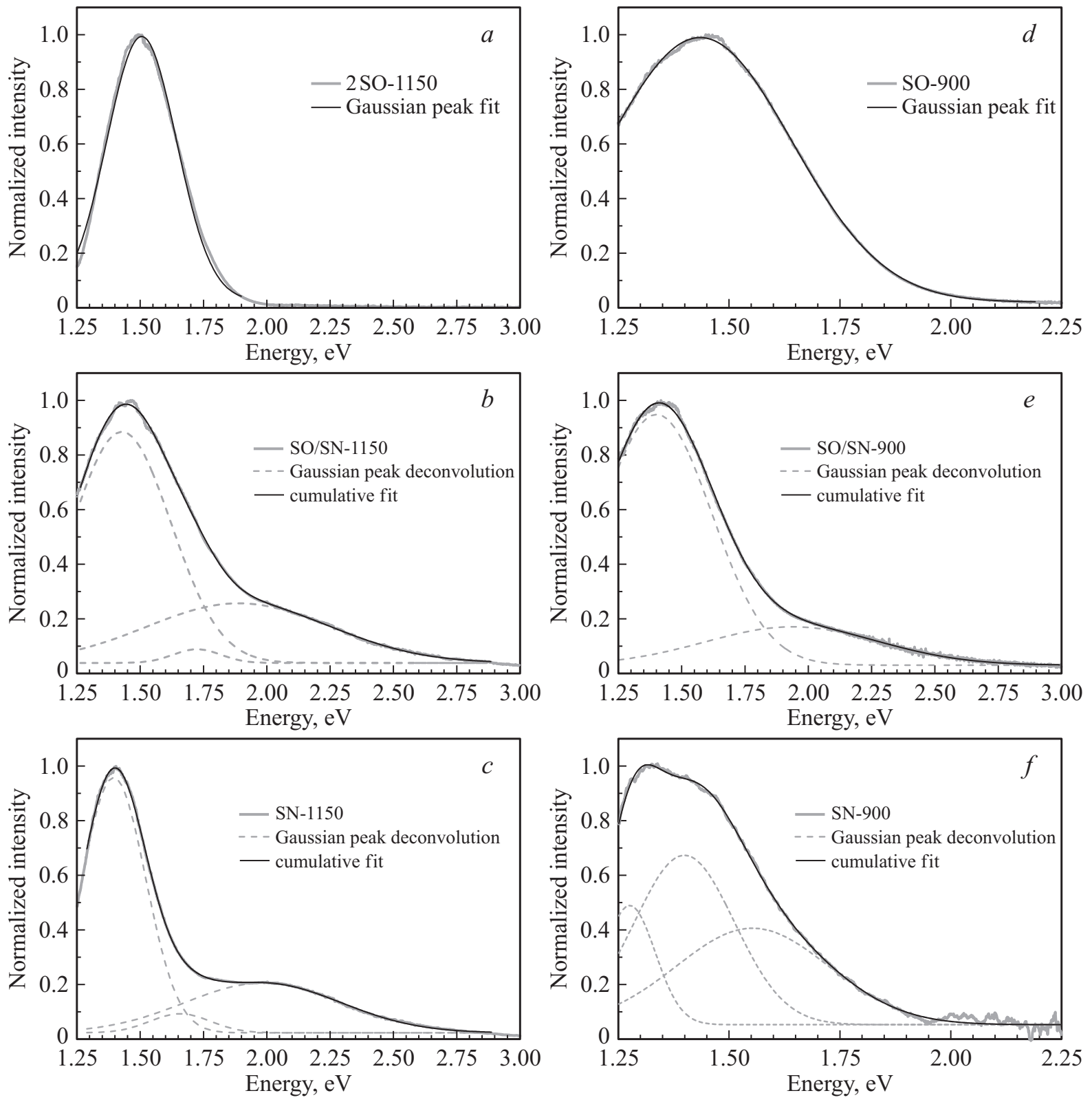

Рис. 1. Спектры фотолюминесценции и их аппроксимация. Образцы, отожженные при $1150^{\circ} \mathrm{C}: \mathrm{SO}-1150(a), \mathrm{SO} / \mathrm{SN}-1150(b)$, $\mathrm{SN}-1150$ (c); образцы, отожженные при $900^{\circ} \mathrm{C}$ : SO-900 (a), SO/SN-900 (e), SN-900 (f). отожженные при $900^{\circ} \mathrm{C}(\mathrm{d})$. Bce спектры нормированы на их максимальные значения.

излучением с длиной волны 248 нм. Для структуры, состоящей из активных слоев субоксида кремния, разделенных барьерными слоями из оксида кремния, в случае отжига при $1150^{\circ} \mathrm{C}$ (образец SO-1150) наблюдается неэкспоненциальная зависимость, наиболее хорошо аппроксимируемая растянутой экспонентой (рис. $2, a$ ):

$$
I(t)=I_{0} \exp \left[-\left(\frac{t}{\tau}\right)^{b}\right]
$$

где $I$ - интенсивность, $I_{0}$ - константа [34], $\tau$ - время релаксации, $b$ лежит в пределах от 0 до 1 . Значение коэффициента $b$, определенное при аппроксимации, равно $(0.56 \pm 0.01), \tau=(10.7 \pm 0.3)$ мкс.
Поскольку кинетика свечения ФЛ в виде растянутой экспоненты наблюдается во множестве различных систем, содержащих кремниевые нанокристаллы в различных матрицах, например, в оксиде кремния [20], а также в пористом кремнии [34], можно сделать вывод, что наблюдаемая нами кинетика ФЛ обусловлена именно наличием кремниевых нанокристаллов, образующихся в активных слоях пленки при высокотемпературном отжиге. Неэкспоненциальный ход кривой затухания ФЛ можно объяснить дисперсией скорости излучательной рекомбинации экситонов в кремниевых нанокристаллах из-за неоднородности размеров нанокристаллов, а также различием в скорости безызлучательной релаксации 

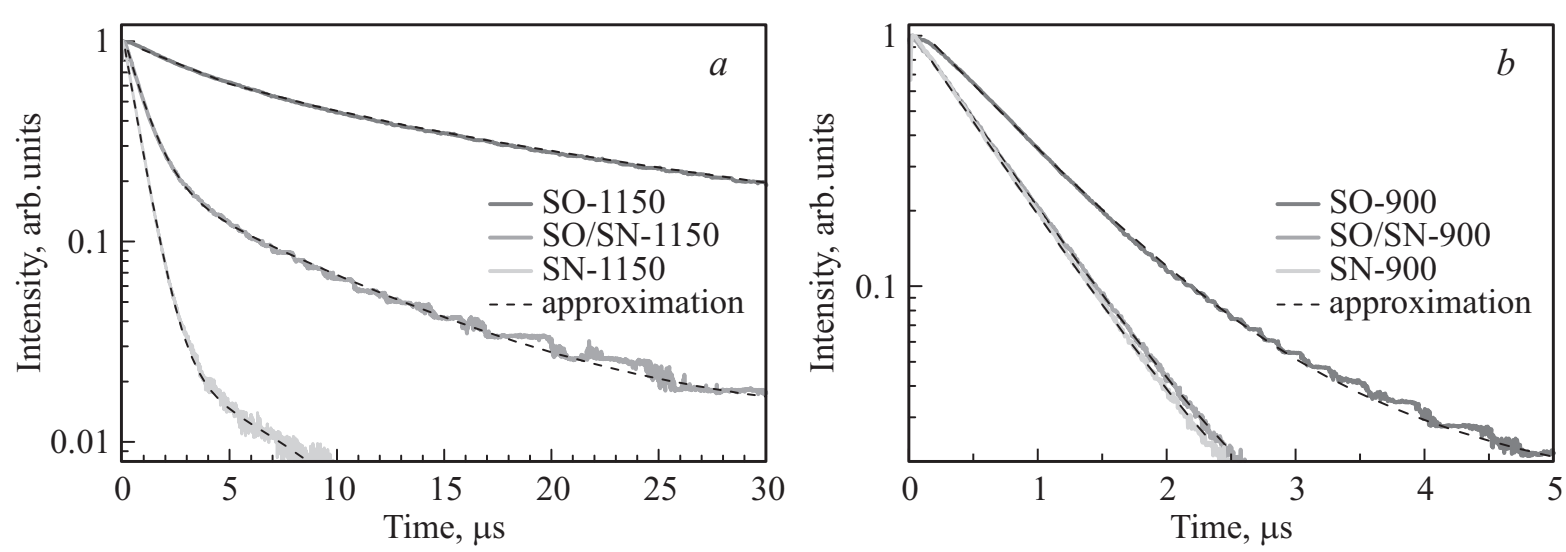

Рис. 2. Кинетика ФЛ образцов, отожженных при $1150(a), 900^{\circ} \mathrm{C}(b)$. Измерения на длине волны 800 нм.

из-за переноса носителей заряда на безызлучательные центры рекомбинации [34].

В данном случае аппроксимации растянутой экспонентой существует следующая связь между временем релаксации $\tau$, определенным по формуле (2), и усредненным временем релаксации $\hat{\tau}$ [34]:

$$
\hat{\tau}=\tau \frac{1}{b} \Gamma\left(\frac{1}{b}\right)
$$

где $\Gamma$ - гамма-функция. Параметр $\tau$, используемый в выражении для растянутой экспоненты (2) и характеризующий кинетику затухания, не является средним временем релаксации $\hat{\tau}$ для данного процесса, поскольку, как было сказано выше, существует распределение времен релаксации ФЛ, вызванное дисперсией скорости излучательной рекомбинации экситонов.

Рассчитанное по формуле (3) значение среднего времени релаксации ФЛ для структуры SO-1150 равно $(17.6 \pm 0.3)$ мкс (см. табл. 2).

Кинетика свечения ФЛ для структур из чередующихся слоев субоксида кремния и нитрида кремния
(SO/SN-1150) или из чередующихся слоев субнитрида и нитрида кремния (SN-1150), отожженных при $1150^{\circ} \mathrm{C}$, также не может быть аппроксимирована одной экспонентой, но может суммой двух экспонент (рис. 2,a). Это позволяет предположить наличие двух каналов релаксации фотолюминесценции, с коротким, $\tau_{0}$, и более длинным, $\tau_{1}$, временами релаксации (см. табл. 2), причем по порядку величины данные времена релаксации совпадают во всех образцах. В данном случае из-за того, что в начальной области кинетики основной вклад вносит быстрая компонента релаксации, для аппроксимации медленной компоненты кинетики была использована простая экспонента, а не растянутая, чтобы избежать избыточного количества параметров аппроксимации.

Уменьшение времени релаксации на начальном участке может быть связано с люминесценцией дефектов [28,33]. Данные дефекты характеризуются моноэкспоненциальной кинетикой с временами $\sim 1$ мкс.

Как видно из рис. 2, $a$, интенсивность ФЛ за первые 5 мкс спадает на порядок для образца $\mathrm{SO} / \mathrm{SN}-1150$, и на два порядка для SN-1150, по сравнению с кинетикой

Таблица 2. Максимумы пиков и времена релаксации ФЛ

\begin{tabular}{|c|c|c|c|}
\hline Образец & Источник ФЛ & $\begin{array}{c}\text { Длина волны } \\
\text { максимума ФЛ, нм }\end{array}$ & $\begin{array}{c}\text { Время } \\
\text { релаксации, мкс }\end{array}$ \\
\hline SO-1150 & Кремниевые нанокристаллы & 838 & $17.6 \pm 0.3$ \\
\hline \multirow{2}{*}{$\mathrm{SO} / \mathrm{SN}-1150$} & Дефекты в аморфной матрице & 660 & $1.027 \pm 0.003$ \\
\hline & Кремниевые нанокристаллы & 867 & $11.53 \pm 0.04$ \\
\hline \multirow{2}{*}{$\mathrm{SN}-1150$} & Дефекты в аморфной матрице & 620 & $0.682 \pm 0.001$ \\
\hline & Кремниевые нанокристаллы & 886 & $16 \pm 3$ \\
\hline \multirow{2}{*}{ SO-900 } & Дефекты в аморфной матрице & \multirow{2}{*}{729} & $0.787 \pm 0.001$ \\
\hline & Аморфные кремниевые нанокластеры & & $6.13 \pm 0.08$ \\
\hline $\mathrm{SO} / \mathrm{SN}-900$ & \multirow{2}{*}{ Дефекты в аморфной матрице } & 885 & $0.596 \pm 0.001$ \\
\hline SN-900 & & 954 & $0.573 \pm 0.001$ \\
\hline
\end{tabular}


ФЛ образца SO-1150. Это связано, вероятно, с большей концентрацией дефектов в слоях, содержащих нитрид кремния, по сравнению со слоями из оксида кремния.

Стоит отметить, что в случае отжига структуры из слоев оксида кремния при $900^{\circ} \mathrm{C}(\mathrm{SO}-900)$ кинетика свечения может быть аппроксимирована суммой двух экспонент (рис. $2, b)$ с характерными временами релаксации $\tau_{0}=(0.787 \pm 0.001)$ мкс и $\tau_{1}=(6.13 \pm 0.08)$ мкс. В двух других структурах, содержащих нитрид кремния и отожженных при $900^{\circ} \mathrm{C}$, кинетика ФЛ имеет экспоненциальный вид и малое время релаксации, $\sim 0.6$ мкс (рис. 2,b). Имеющихся на данный момент данных недостаточно, чтобы однозначно интерпретировать наблюдаемую форму кривых затухания люминесценции. Значения времен релаксации для всех исследованных структур приведены в табл. 2 .

\section{4. Заключение}

Таким образом, исследование ФЛ сверхрешеток на основе оксида и нитрида кремния, отожженных при температурах 900 и $1150^{\circ} \mathrm{C}$, выявило наличие следующих особенностей данного процесса.

Обнаружено, что отжиг при температуре $1150^{\circ} \mathrm{C}$ приводит к возникновению ФЛ с максимумом в диапазоне $1.40-1.48$ эВ для всех исследованных образцов. Данный пик может быть объяснен экситонным механизмом ФЛ в кремниевых нанокристаллах, сформированных при высокотемпературном отжиге. Размер нанокристаллов, оцененный по положению пика ФЛ, составляет от $(3.1 \pm 0.8)$ до $(3.6 \pm 0.6)$ нм, что соответствует толщине слоев с избытком кремния в исследованных структурах. В структурах, содержащих нитрид кремния, кроме основного пика наблюдаются также дополнительные пики ФЛ, вызванные, скорее всего, дефектами на границе нанокристаллов и в объеме аморфной матрицы $\mathrm{Si}_{3} \mathrm{~N}_{4}$. Данное предположение подтверждается неэкспоненциальным видом кинетики ФЛ данных образцов, предполагающим наличие двух каналов релаксации: более быстрый связан с дефектами матрицы, более медленный обусловлен наличием нанокристаллов кремния.

Наблюдаемые спектры ФЛ образцов, отожженных при $900^{\circ} \mathrm{C}$, предполагают наличие тех же механизмов, что и в случае отжига при $1150^{\circ} \mathrm{C}$, только с учетом наличия аморфных, а не кристаллических кремниевых частиц в активных слоях пленки, поскольку температура отжига $900^{\circ} \mathrm{C}$ недостаточна для формирования кремниевых нанокристаллов. Для всех трех образцов этого типа кинетика ФЛ существенно ускорялась по сравнению с кинетикой ФЛ структур, отожженных при более высокой температуре.

Работа выполнена при финансовой поддержке Российского фонда фундаментальных исследований (гранты № 16-32-80066 мол_эв_а, 15-32-21153 мол_а_вед и 14-22-01086 офи_м).
Авторы выражают благодарность Лаборатории нанотехнологий технического факультета Университета Альберта-Людвига, г. Фрайбург за предоставленные образцы.

\section{Список литературы}

[1] P.F. Trwoga, A.J. Kenyon, C.W. Pitt. J. Appl. Phys., 83, 3789 (1998).

[2] D.M. Zhigunov, V.N. Seminogov, V.Yu. Timoshenko, V.I. Sokolov, V.N. Glebov, A.M. Malyutin, N.E. Maslova, O.A. Shalygina, S.A. Dyakov, A.S. Akhmanov, V.Ya. Panchenko, P.K. Kashkarov. Physica E, 41, 1006 (2009).

[3] T. Creazzo, B. Redding, E. Marchena, J. Murakowski, D.W. Prather. J. Luminesc., 130, 631 (2010).

[4] A. Zelenina, S.A. Dyakov, D. Hiller, S. Gutsch, V. Trouillet, M. Bruns, S. Mirabella, P. Löper, L. López-Conesa, J. López-Vidrier, S. Estradé, F. Peiró, B. Garrido, J. Bläsing, A. Krost, D.M. Zhigunov, M. Zacharias. J. Appl. Phys., 114, 184311 (2013).

[5] A.M. Hartel, D. Hiller, S. Gutsch, P. Löper, S. Estradé, F. Peiró, B. Garrido, M. Zacharias. Thin Sol. Films, 520 (1), 121 (2011).

[6] R.J. Walters, J. Kalkman, A. Polman, H.A. Atwater, M.J.A. de Dood. Phys. Rev. B, 73, 132302 (2006).

[7] Jonghoon Choi, Nam Sun Wang, Vytas Reipa. Langmuir, 23, 3388 (2007).

[8] E. Quiroga-González, W. Bensch, M. Aceves-Mijares, Z. Yu, R. López-Estopier, K. Monfil-Leyva. Thin Sol. Films, 519 (22), 8030 (2011).

[9] Y. Li, P. Liang, Zh. Hu, Sh. Guo, H. Cai, F. Huang, J. Sun, N. Xu, J. Wu. Appl. Surf. Sci., 320, 804 (2014).

[10] S. Veprek, G.J. Maritza Veprek-Heijman. J. Vac. Sci. Technol. A, 33, 043001 (2015).

[11] A.V. Emelyanov, A.G. Kazanskii, P.A. Forsh, D.M. Zhigunov, M.V. Khenkin, N.N. Petrova, A.V. Kukin, E.I. Terukov, P.K. Kashkarov. J. Nanoelectron. Optoelectron., 10 (5), 649 (2015).

[12] A.V. Emelyanov, A.G. Kazanskii, M.V. Khenkin, P.A. Forsh, P.K. Kashkarov, M. Gecevicius, M. Beresna, P.G. Kazansky. Appl. Phys. Lett., 101 (8), 081902 (2012).

[13] E.A. Konstantinova, V.A. Demin, A.S. Vorontzov, Y.V. Ryabchikov, I.A. Belogorokhov, L.A. Osminkina, P.A. Forsh, P.K. Kashkarov, V.Y. Timoshenko. J. Non-Cryst. Sol., 352, 1156 (2006).

[14] Y.-H. So, Sh. Huang, G. Conibeer, M.A. Green. Thin Sol. Films, 519, 5408 (2011).

[15] T.V. Torchynska, J.L. Casas Espinola, L. Khomenkova, E. Vergara Hernandez, J.A. Andraca Adame, A. Slaoui. Mater. Sci. Semicond. Proc., 37, 46 (2015).

[16] N. Hafsi, H. Bouridah, M.R. Beghoul, H. Haoues. J. Appl. Phys., 117, 063105 (2015).

[17] B.M. Monroy, G. Santana, J. Aguilar-Hernández, A. Benami, J. Fandiño, A. Ponce, G. Contreras-Puente, A. Ortiz, J.C. Alonso. J. Luminesc., 121, 349 (2006).

[18] L.V. Goncharova, P.H. Nguyen, V.L. Karner, R. D’Ortenzio, S. Chaudhary, C.R. Mokry, P.J. Simpson. J. Appl. Phys., 118, 224302 (2015). 
[19] О.И. Ерошова, П.А. Перминов, А.А. Ежов, Л.А. Головань, С.В. Заботнов, П.К. Кашкаров, М.Б. Гонгальский. Кристаллография, 57 (6), 942 (2012).

[20] J. Linnros, N. Lalic, A. Galeckas, V. Grivickas. J. Appl. Phys., 86, 6128 (1999).

[21] G. Scardera, T. Puzzer, I. Perez-Wurfl, G. Conibeer. J. Cryst. Growth, 310, 3680 (2008).

[22] W. Liao, X. Zeng, X. Wen, X. Chen, W. Wang. Vacuum, 121, 147 (2015).

[23] T.-Y. Kim, N.-M. Park, K.-H. Kim, G. Y. Sung, Y.-W. Ok, T.-Y. Seong, Ch.-J. Choi. Appl. Phys. Lett., 85, 5355 (2004).

[24] J. Kistner, X. Chen, Y. Weng, H.P. Strunk, M.B. Schubert, J.H. Werner. J. Appl. Phys., 110, 023520 (2011).

[25] P.D. Nguyen, D.M. Kepaptsoglou, Q.M. Ramasse, A. Olsen. Phys. Rev. B, 85, 085315 (2012).

[26] L.V. Mercaldo, P.D. Veneri, E. Esposito, E. Massera, I. Usatii, C. Pivato. Mater. Sci. Eng. B, 159, 77 (2009).

[27] A. Zelenina, A. Sarikov, D.M. Zhigunov, C. Weiss, N. Zakharov, P. Werner, L. López-Conesa, S. Estradé, F. Peiró, S.A. Dyakov, M. Zacharias. J. Appl. Phys., 115, 244304 (2014).

[28] D. Hiller, A. Zelenina, S. Gutsch, S.A. Dyakov, L. López-Conesa, J. López-Vidrier, S. Estradé, F. Peiró, B. Garrido, J. Valenta, M. Kořínek, F. Trojánek, P. Malý, M. Schnabel, C. Weiss, S. Janz, M. Zacharias. J. Appl. Phys., 115, 204301 (2014).

[29] M.V. Wolkin, J. Jorne, P.M. Fauchet. Phys. Rev. Lett., 82 (1), 197 (1999).

[30] P.A. Pundur, J.G. Shavalgin, V.A. Gritsenko. Phys. Status Solidi A, 94, 107 (1986).

[31] S.V. Deshpande, E. Gulari, S.W. Brown, S.C. Rand. J. Appl. Phys., 77, 6534 (1995).

[32] J. Robertson. Phil. Mag. B, 69, 307 (1994).

[33] E.G. Barbagiovanni, D.J. Lockwood, P.J. Simpson, L.V. Goncharova. J. Appl. Phys., 111, 034307 (2012).

[34] T. Nakamura, S. Adachi. J. Luminesc., 132, 3019 (2012).

Редактор Л.В. Шаронова

\section{Photoluminescent properties of amorphous and crystalline silicon nanoclusters in silicon nitride and silicon oxide superlattices}

\author{
D.V. Shuleiko ${ }^{1}$, S.V. Zabotnov ${ }^{1,2,3}$, D.M. Zhigunov ${ }^{1}$, \\ A.A. Zelenina ${ }^{4}$, I.A. Kamenskih ${ }^{1,2}$, P.K. Kashkarov ${ }^{1,2,3}$ \\ ${ }^{1}$ Lomonosov Moscow State University \\ (Faculty of Physics), \\ 119991 Moscow, Russia \\ 2 National Research Centre „Kurchatov Institute“, \\ 123182 Moscow, Russia \\ ${ }^{3}$ Moscow Institute of Physics and Technology \\ (Department of Nano-, Bio-, Information Technology \\ and Cognitive Science), \\ 141700 Dolgoprudny, Russia \\ ${ }^{4}$ Novosibirsk State University, \\ 630090 Novosibirsk, Russia
}

\begin{abstract}
Photoluminescent properties of silicon nitride and silicon oxide superlattices fabricated by plasma-enhanced chemical vapor deposition followed by annealing were investigated. Photoluminescence peaks at $\sim 1.45 \mathrm{eV}$ were detected in the structures annealed at $1150^{\circ} \mathrm{C}$, due to exiton recombination in silicon nanocrystals formed by annealing. Also a number of recombination peaks, caused by defects in the silicon nitride matrix and on the nanocrystal interfaces, were revealed. Structures annealed at at $900^{\circ} \mathrm{C}$ possess a number of peaks in $1.3-2.0 \mathrm{eV}$ spectral range, caused by defects as well as exiton recombination in amorphous silicon nanoclusters formed at this annealing temperature. The observed photoluminescence features are confirmed by the nature of its kinetics.
\end{abstract}

